\title{
The stability analysis of dam walls using artificial neural network
}

\author{
Professor Dr. Sorush Niknamian \\ Board Member of Weston A Price Foundation, Washington DC, USA \\ Email: so.niknamian@gmail.com
}

\begin{abstract}
The stability of rock slopes of the walls of Roodbar dam in Lorestan is investigated using multi-layer Perceptron of artificial neural network algorithm. Then, the stability of rock slopes is studied by considered factors affecting stability at before and after impounding dam. The calculation is done on the factors affecting stability using artificial neural network algorithm. Finally, the results show that rock slopes of the walls of Roodbar dam in Lorestan in a dry state are stable at seventeen modes and unstable at three modes. Also, in a saturated state are stable at fourteen modes and unstable at six modes, furthermore have generally a little stability. The results of this paper indicated that the calculation are augmentable with experimental results.
\end{abstract}

Keywords: Stability, Dam Walls, artificial neural network

\section{Introduction}

The study of rock slope for different water and soil structures has been considered in the past few decades [1-4]. The effective parameters to the stability of rock slopes are adhesion coefficient, friction angle, topography dip, slide dip, total water pressure in fractures, pore water pressure, fracture depth, depth of fractures saturated by water, the total height of slid, density and area [5]. The geological, hydrological and topographical properties are studied using these parameters. Among the slopes, it can be mentioned the slopes that are stable in a dry state, and in a saturated state, they create an unstable mass because of reduced shear strength parameters [5].

Rock instabilities in the dry state are essentially more stable than the instabilities in a saturation state. In saturation state, their stability is reduced due to a decrease in shear strength parameters [5].

It is difficult to take into account all of the above parameters in the calculation. Therefore, the study of all mentioned parameters is done using different numerical methods such as Markov chain, Fuzzy logic and artificial neural network [6-8]. The stability of rock slopes is studied using different method such as Markov chain, Fuzzy logic and artificial neural network at the past decades in many researchers [8-18].

Litho-logical, meteorological and morphological conditions of the area are the most important factors to study of rock slopes [5].

In the study, it has been attempted to analyze the stability of rock instabilities in dry and saturation states in Roodbar dam using the fuzzy logic.

\section{Materials and methods}

The coordinates of area study in this paper is $49^{\circ} 41^{\prime} 37^{\prime \prime}$ longitude and $32^{\circ} 54^{\prime \prime} 23^{\prime \prime}$ latitude. Also, this area is located in $100 \mathrm{~km}$ southern Aligudarz, Lorestan province and within the Zagros mountains (Figure 1) [4].

Slope instability caused by various conditions and parameters such as geological, hydrological, tectonic parameters and etc. Therefore, the calculations of these parameters simultaneously are very difficult. Therefore, these calculations are done using artificial neural network algorithm.

Artificial neural network is a massive parallel processor composed of simple processing units. Also, it's most important advantage compared to the other intelligent systems is the ability to learn the network from the environment and increase efficiency during the training. The training algorithm is a method used to train the network and its duty is the weight modification of network neurons so that it can guide us toward a predetermined goal.

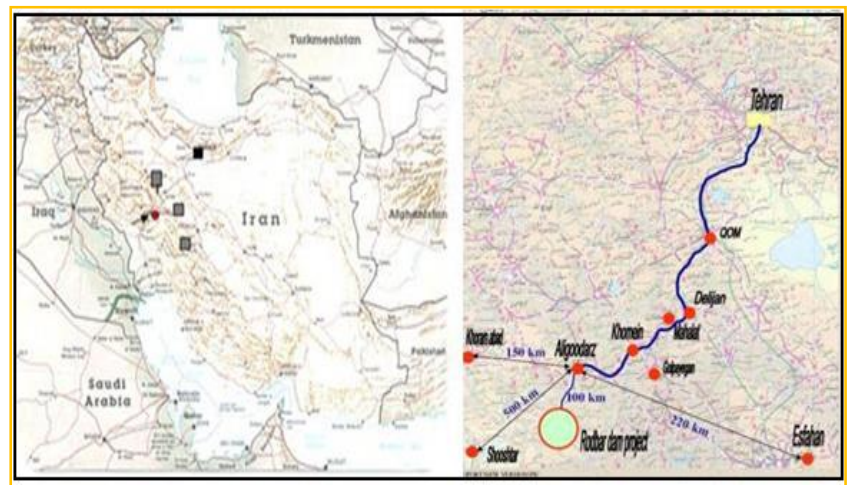

FIGURE 1: The position of the study area (no scale)

Figure 2 shows the model of a node as a basic processing unit in a neural network and its mathematical relations, which $\mathrm{Xij}, \mathrm{Wij}, \mathrm{f}, \mathrm{bj}, \mathrm{Oj}$ are inputs for the node $\mathrm{j}$, weights of the network, actuation function, the value of bias and output for the node $\mathrm{j}$ respectively [18]. 


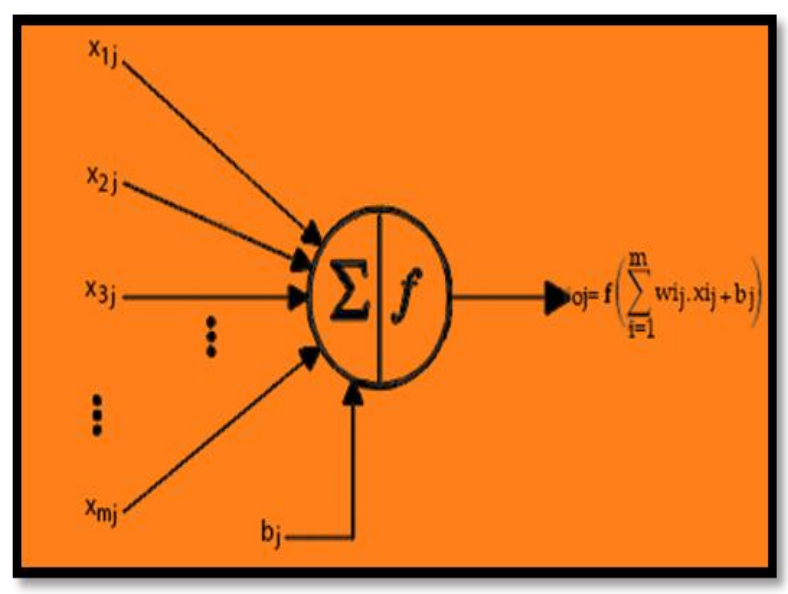

FIGURE 2: Mathematical model of node

MLP has been successfully used to solve the complex and various problems. The network with three inputs, output and middle layers, differentiable functions and a sufficient number of neuron in the middle layer are able to estimate the non-linear function with any degree of complexity [19].

Therefore, the three-layer neural network is used for modeling in this study. The network is trained using a learning method by the observer and back propagation algorithm which accordingly, the error is corrected. Backpropagation learning algorithm is formed on two forward and feedback paths from among the different layers (figure 3 ).

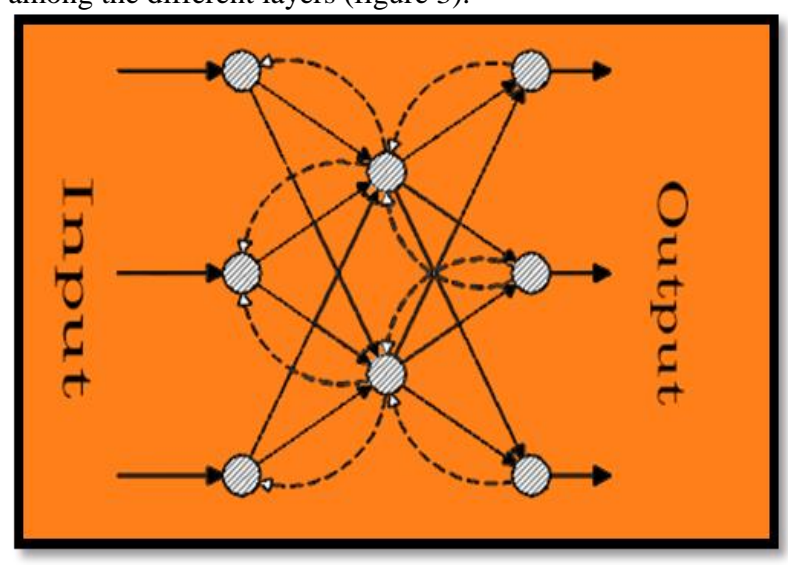

FIGURE 3: Directions of two signal flow in MLP

On the forward path shown as continuous vectors, an input vector is applied to the input nodes of the network, which consequently, it is spread in a layer by layer on the net. Finally, a set of output is reported as the true response of the network. All weights of the network remain fixed on the forward path. On the other hand, the weights are modified on the backward path in according to the error correction code. The real response of the network will be specifically deducted from the favorable response to generate an error signal; then, the error signal is backwardly spread on the network. In order to deliver the real response to the desirable response of $\mathrm{Wji}$, the weights will be modified. The relation (1) shows $\Delta W_{i j}$ correction applied to the weights connecting the node $\mathrm{i}$ to the node $\mathrm{j}[20]$.

$$
\begin{aligned}
& \Delta W_{i j}(n)=\eta \delta_{j}(n) y_{j}(n)+\alpha \Delta W_{j i}(n-1) \\
& \Delta W_{i j}(n) \eta_{\text {and }} y_{i}(n)
\end{aligned}
$$

are weight modification to the node inputs, learning rate and the input signal of node respectively. Also, $\alpha$ is a positive value as momentum constant and $\delta_{j}(n)$ is equaled to the derivative $\mathrm{O} j$ in the error signal related to the neuron $\mathrm{j}$.

\section{Factors affecting stability of rock instabilities in study area}

\subsection{Structural (Geological) properties}

From the viewpoint of geology, the study area is located in the crush zone of Zagros. Often, the areas include an enormous mass of tectonized materials from the type of Dolomite and Dolomitic limestone fractured rocks. Structural properties such as sliding slope and fracture depth are considered as determinants of the stability of rock instabilities in the area.

The results of the studies suggest the rock instability in the slopes above 60 degrees. The properties of the lithologic units are shown in Table 1.

TABLE 1: Structural properties of lithologic units of study

\begin{tabular}{|c|c|c|}
\hline Factor & Fracture Depth $(\mathrm{Z})(\mathrm{m})$ & $\begin{array}{c}\text { Slide Dip ( }(\Psi \mathrm{p}) \\
\left({ }^{\circ}\right)\end{array}$ \\
\hline Value & 5 & 60 \\
\hline
\end{tabular}
area

\subsection{Geotechnical properties}

Since the geotechnical properties are effective on the stability of rock instabilities, various geotechnical tests were done on the rock samples in the area. Finally, the numeral values for the factors as friction angle, adhesion coefficient, and density were determined using the Rock Lab software (as shown in Table 2).

TABLE 2: Numeral values for geotechnical properties using Rock lab software

\begin{tabular}{lccc}
\hline Factor & $\begin{array}{c}\text { Adhesion } \\
\text { Coefficient }(\mathrm{C}) \\
(\mathrm{MPa})\end{array}$ & $\begin{array}{c}\text { Friction } \\
\text { Angle }(\phi)\left(^{\circ}\right)\end{array}$ & $\begin{array}{c}\text { Density }(\gamma) \\
(\mathrm{kg} / \mathrm{m} 3)\end{array}$ \\
\hline Value & 0.4 & 40 & 2330 \\
\hline
\end{tabular}

\subsection{Topographical properties}

Topographical properties are among the factors affecting the stability of rock instabilities. The results indicate that there are almost identical values for topography slope ( $\Psi$ f) 60 to 80 degrees, the total height of solid (H) and area (A) for any factor (as shown in Table 3).

TABLE 3: Numeral values for topographical properties of study area

Factor Topography Slope $\quad$ Total Height of Area (A)




\begin{tabular}{cccc}
\hline & $(\Psi \mathrm{f})\left({ }^{\circ}\right)$ & Slid $(\mathrm{H})(\mathrm{m})$ & $(\mathrm{m} 2)$ \\
\hline Value & 69 & 15 & 2 \\
\hline
\end{tabular}

\subsection{Hydrogeological properties}

Hydrogeological properties as total water pressure in fractures $(V)$, pore water pressure $(\mathrm{U})$ and depth of fractures saturated by water $(\mathrm{Zw})$ are the most important factors affecting the instability of rock instabilities. The values for the factors are quietly different before dam inundation (dry state) and after it (saturated state). The values are presented in Table 4

TABLE 4: Numeral values for hydrogeological properties in dry and saturation state area

\begin{tabular}{cccc}
\hline Factor & $\begin{array}{c}\text { Total Water } \\
\text { Pressure in } \\
\text { Fractures } \\
(\mathrm{V})(\mathrm{Kpa})\end{array}$ & $\begin{array}{c}\text { Pore } \\
\text { Water } \\
\text { Pressure } \\
(\mathrm{U})(\mathrm{Kpa})\end{array}$ & $\begin{array}{c}\text { Depth of } \\
\text { Fractures } \\
\text { Saturated by } \\
\text { Water }(\mathrm{Zw})(\mathrm{m})\end{array}$ \\
\hline $\begin{array}{c}\text { Value in } \\
\text { dry state }\end{array}$ & 4 & 0 & 2 \\
\hline $\begin{array}{c}\text { Value in } \\
\text { saturation } \\
\text { state }\end{array}$ & 108 & 20 & 2 \\
\hline
\end{tabular}

\section{Result and discussion}

\subsection{Selected network architecture}

In the study, neural networks software has been used to predict the stability of rock slopes using MLP [21].
Neural networks software is a powerful and dynamic program to create the different systems of the artificial neural network. Various problems can be designed by the program. Training and testing the data and developing a variety of networks in order to solve the complex and combined problems can be mentioned as the other features of the software. Non-linear regression and multi-dimensional functions are applied to calculate the error. The most important feature of the program is its unique graphical features which make it very easy to use [22].

The parameters influenced on modeling the stability of rock slopes considered as model inputs can be seen in Table 5.

Before training the network, the data collected need to be processed for the network. Therefore, all properties of the sample are firstly set on the input-output table. Then, the inputs and outputs are limited to the intended interval using the statistical methods, because if the inputs provided to the network are large, the sum of weighted inputs to the next layer of neurons will be great and there will be trouble on training the data even with small weights in the network. Thus, all input data will be at desired intervals, resulting in reduced network modeling error.

To compare the different structures, some indices are required to evaluate the function of the proposed model in the entire data model and compared with experimental results.

TABLE 5: Network inputs for scenarios forty in the area

\begin{tabular}{|c|c|c|c|c|c|c|c|c|c|c|c|}
\hline & 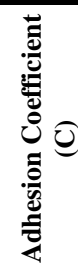 & 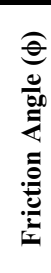 & 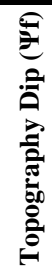 & 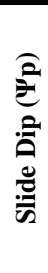 & 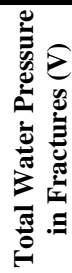 & 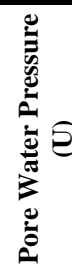 & 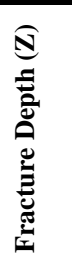 & 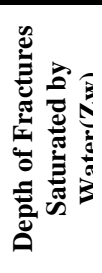 & 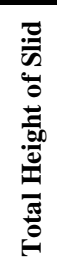 & 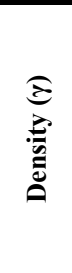 & 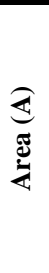 \\
\hline 1 & 0.41 & 40 & 63 & 61 & 8 & 3 & 4.3 & 2 & 15 & 2.33 & 2 \\
\hline 2 & 0.43 & 42 & 61 & 60 & 10 & 2 & 4.2 & 2 & 15 & 2.33 & 2 \\
\hline 3 & 0.43 & 42 & 60 & 62 & 9 & 2 & 4.5 & 2 & 15 & 2.33 & 2 \\
\hline 4 & 0.45 & 44 & 62 & 61 & 8 & 4 & 4.1 & 2 & 15 & 2.33 & 2 \\
\hline 5 & 0.41 & 42 & 61 & 61 & 11 & 5 & 4.4 & 1 & 15 & 2.33 & 2 \\
\hline 6 & 0.40 & 41 & 64 & 60 & 9 & 3 & 4.5 & 1 & 15 & 2.33 & 2 \\
\hline 7 & 0.44 & 42 & 63 & 60 & 13 & 3 & 4.6 & 1 & 15 & 2.33 & 2 \\
\hline
\end{tabular}




\begin{tabular}{|c|c|c|c|c|c|c|c|c|c|c|c|}
\hline 8 & 0.42 & 41 & 61 & 62 & 9 & 5 & 4.4 & 1 & 15 & 2.33 & 2 \\
\hline 9 & 0.42 & 41 & 65 & 60 & 8 & 3 & 4.6 & 2 & 15 & 2.33 & 2 \\
\hline 10 & 0.41 & 42 & 64 & 61 & 12 & 5 & 4.3 & 2 & 15 & 2.33 & 2 \\
\hline 11 & 0.41 & 39 & 66 & 65 & 14 & 4 & 4.9 & 2 & 15 & 2.33 & 2 \\
\hline 12 & 0.40 & 39 & 68 & 64 & 13 & 3 & 5 & 2 & 15 & 2.33 & 2 \\
\hline 13 & 0.38 & 37 & 69 & 66 & 12 & 6 & 5.1 & 1 & 15 & 2.33 & 2 \\
\hline 14 & 0.37 & 38 & 68 & 68 & 19 & 5 & 5.2 & 1 & 15 & 2.33 & 2 \\
\hline 15 & 0.38 & 36 & 70 & 67 & 24 & 5 & 5 & 1 & 15 & 2.33 & 2 \\
\hline 16 & 0.44 & 42 & 63 & 62 & 24 & 3 & 4.3 & 1 & 15 & 2.33 & 2 \\
\hline 17 & 0.43 & 43 & 66 & 61 & 10 & 3 & 4.1 & 2.3 & 15 & 2.33 & 2 \\
\hline 18 & 0.45 & 41 & 64 & 60 & 18 & 2 & 4.3 & 2.2 & 15 & 2.33 & 2 \\
\hline 19 & 0.45 & 42 & 64 & 60 & 14 & 5 & 4.1 & 2.1 & 15 & 2.33 & 2 \\
\hline 20 & 0.39 & 38 & 62 & 64 & 25 & 6 & 4.7 & 2.5 & 15 & 2.33 & 2 \\
\hline 21 & 0.42 & 43 & 65 & 60 & 82 & 15 & 4.3 & 2.3 & 15 & 2.33 & 2 \\
\hline 22 & 0.43 & 41 & 63 & 61 & 83 & 14 & 4.1 & 3.1 & 15 & 2.33 & 2 \\
\hline 23 & 0.43 & 43 & 66 & 60 & 79 & 13 & 4.2 & 3.2 & 15 & 2.33 & 2 \\
\hline 24 & 0.38 & 39 & 68 & 65 & 74 & 14 & 4.9 & 3.6 & 15 & 2.33 & 2 \\
\hline 25 & 0.43 & 42 & 63 & 60 & 76 & 12 & 4.4 & 3.3 & 15 & 2.33 & 2 \\
\hline 26 & 0.45 & 43 & 65 & 61 & 68 & 14 & 4.3 & 1 & 15 & 2.33 & 2 \\
\hline 27 & 0.44 & 41 & 64 & 60 & 77 & 13 & 4.3 & 1 & 15 & 2.33 & 2 \\
\hline 28 & 0.43 & 42 & 64 & 60 & 75 & 13 & 4.1 & 1 & 15 & 2.33 & 2 \\
\hline 29 & 0.38 & 40 & 66 & 68 & 99 & 18 & 4.8 & 3 & 15 & 2.33 & 2 \\
\hline 30 & 0.37 & 38 & 68 & 66 & 98 & 19 & 4.6 & 2.8 & 15 & 2.33 & 2 \\
\hline 31 & 0.38 & 36 & 67 & 69 & 94 & 19 & 4.9 & 3 & 15 & 2.33 & 2 \\
\hline 32 & 0.37 & 37 & 67 & 71 & 94 & 20 & 4.5 & 2.7 & 15 & 2.33 & 2 \\
\hline 33 & 0.36 & 39 & 68 & 68 & 96 & 18 & 4.8 & 3.1 & 15 & 2.33 & 2 \\
\hline 34 & 0.38 & 38 & 66 & 60 & 90 & 17 & 4.7 & 3.1 & 15 & 2.33 & 2 \\
\hline 35 & 0.40 & 36 & 68 & 72 & 93 & 17 & 4.6 & 3.1 & 15 & 2.33 & 2 \\
\hline 36 & 0.39 & 38 & 68 & 70 & 95 & 19 & 4.9 & 3.3 & 15 & 2.33 & 2 \\
\hline 37 & 0.39 & 39 & 67 & 67 & 72 & 15 & 4.8 & 4.2 & 15 & 2.33 & 2 \\
\hline 38 & 0.38 & 38 & 70 & 66 & 76 & 14 & 4.6 & 4.1 & 15 & 2.33 & 2 \\
\hline 39 & 0.37 & 36 & 68 & 68 & 74 & 16 & 4.7 & 4.4 & 15 & 2.33 & 2 \\
\hline 40 & 0.40 & 38 & 69 & 69 & 64 & 19 & 5 & 4.3 & 15 & 2.33 & 2 \\
\hline
\end{tabular}

In the study, two indicators of root mean square error (RMS) and an increase in the correlation coefficient (R) was used to evaluate the model. Cross-Validation method has been used to increase the generalization power in order to stop the training, Network parameters were systematically designed with the aim of reduced root mean square error (RMS) and increased correlation coefficient (R) between the actual and forecast data. In the method, the optimal network had 10 nodes in the middle layer, and the learning coefficients in the middle and output layers and momentum coefficient were obtained $0.7,0.3$ and 0.2 respectively. The lowest error index and highest correlation in the network were related to a hyperbolic tangent transfer function for the middle layer and sigmoid function for the output layer respectively. Finally, the network architecture was obtained in a form of $11 * 10 * 1$, a network with 11 inputs, 10 intermediate nodes, and outputs.

Figure 4 shows a view of the network. Eventually, the values of 0.037 and 0.27 were obtained for the root mean square error after training the network.

In order to train the network, the file of training data will be added to the program. The file is read line by line through the program, and according to the training data, the weights will vary; In other words, the network is trained. When the program reaches the last line of data, it is returned to the beginning of the file and the process is repeated again. As seen in Figure 4, since the error of assessment data reaches the lowest value, training will be stopped after reading 70,000 lines of data files. 


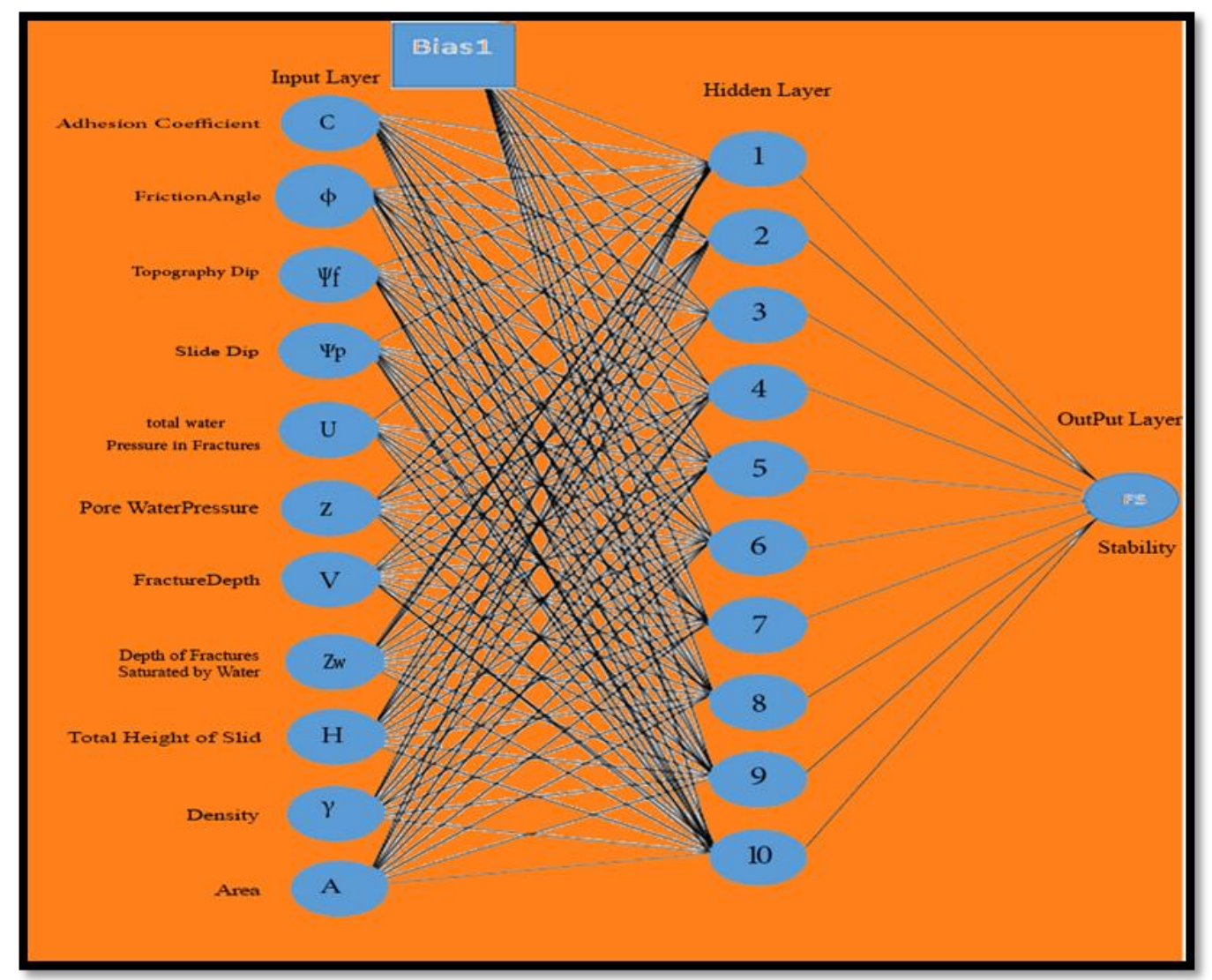

FIGURE 4: view of the neural network used in modeling

TABLE 6: SAFETY FACTOR FOR SCENARIOS FORTY IN THE AREA

\begin{tabular}{|c|c|c|c|}
\hline $\begin{array}{l}\text { states/ } \\
\text { modes }\end{array}$ & $\begin{array}{l}\text { Safety } \\
\text { Factor }\end{array}$ & $\begin{array}{l}\text { states/ } \\
\text { modes }\end{array}$ & $\begin{array}{l}\text { Safety } \\
\text { Factor }\end{array}$ \\
\hline 1 & 1.251 & 21 & 1.182 \\
\hline 2 & 1.246 & 22 & 1.258 \\
\hline 3 & 1.250 & 23 & 1.163 \\
\hline 4 & 1.423 & 24 & 1.214 \\
\hline 5 & 1.391 & 25 & 1.183 \\
\hline 6 & 1.331 & 26 & 1.146 \\
\hline 7 & 1.312 & 27 & 1.261 \\
\hline 8 & 1.382 & 28 & 1.211 \\
\hline 9 & 1.272 & 29 & 1.051 \\
\hline 10 & 1.278 & 30 & 1.061 \\
\hline 11 & 1.269 & 31 & 0.958 \\
\hline 12 & 1.273 & 32 & 1.063 \\
\hline 13 & 0.996 & 33 & 0.983 \\
\hline 14 & 0.998 & 34 & 0.961 \\
\hline 15 & 0.999 & 35 & 0.996 \\
\hline 16 & 1.251 & 36 & 1.147 \\
\hline 17 & 1.256 & 37 & 1.253 \\
\hline 18 & 1.267 & 38 & 1.265 \\
\hline 19 & 1.268 & 39 & 1.268 \\
\hline 20 & 0.917 & 40 & 1.017 \\
\hline
\end{tabular}

If the network is more trained, it might memorize the data. When learning is more than enough, it will lose its ability to generalize. It occurs when a network error on the assessment data begin to rise.

\subsection{Safety factor}

Considering the factors of instability in the area, the parameters affecting the stability of rock instabilities were studied using the method. The occurrences in the area are 40 Scenarios based on eleven factors (Table 6).

\section{Conclusion}

In this paper, we calculate the stability rock slope of dam walls using artificial neural network method. In order to, we give affecting factor of stability as input data of artificial neural network method. Finally, the results obtained from the study show that the stability has decreased due to reduced adhesion and friction angle and increased failure slope and land slope, so that the confidence coefficient is varied between 0.9 to 0.99 , and it has decreased in the case of 29 to 40, 20 and 24 due to increased water pressure in the joints and water pore pressure in the failure surface and cracks depth so that the confidence coefficient varies between 0.9 to 0.96 .

Considering the stability analysis, the range is between 0.9 to 1.3 that it indicates the stability of the majority of the slope with the joints of 60 to 80 degrees in the dry state and instability on the most slopes in a saturated state.

The simulation results indicate that the proposed neural network is able to withstand slope. The network behavior complies with the laws and 
principles of mechanics. Finally, it can be said that the neural network has the ability to model through the simple parameters usually done at early stages of explorations.

\section{References}

[1] Valipour, Mohammad, Mohammad Ebrahim Banihabib, and Seyyed Mahmood Reza Behbahani. "Comparison of the ARMA, ARIMA, and the autoregressive artificial neural network models in forecasting the monthly inflow of Dez dam reservoir." Journal of hydrology 476 (2013): 433-441.

[2] Gupta, Neha. "Artificial neural network." Network and Complex Systems 3, no. 1 (2013): 24-28.

[3] Kayastha, P., M. R. Dhital, and F. De Smedt. "Application of the analytical hierarchy process (AHP) for landslide susceptibility mapping: a case study from the Tinau watershed, west Nepal." Computers \& Geosciences 52 (2013): 398-408.

[4] Zarei, Shapoor, Sami Setayesh, and Shahram Zarei. "Technical and financial reviewing of Constructive projects (Case Study: Roodbar Dam, Iran)." (2012) 2, 63-67.

[5] Stimpson, B. "Modelling materials for engineering rock mechanics." In International Journal of Rock Mechanics and Mining Sciences \& Geomechanics Abstracts, vol. 7, no. 1, pp. 77-121. Pergamon, 1970.

[6] Xue, X., Yang, X. and Li, P., 2017. Evaluation of Ground Vibration Due to Blasting Using Fuzzy Logic. Geotechnical and Geological Engineering, 35(3), pp.1231-1237.

[7] Lin, Jun-zhi, and Ze-long Liang. "The Application of Extension Neural Network in the Stability Analysis of High Rock Slope." Electronic Journal of Geotechnical Engineering 21, no. 7 (2016): 1705-1716.

[8] Li, Dian-Qing, Xiao-Hui Qi, Zi-Jun Cao, Xiao-Song Tang, Kok-Kwang Phoon, and Chuang-Bing Zhou. "Evaluating slope stability uncertainty using coupled Markov chain." Computers and Geotechnics 73 (2016): 72-82.

[9] Jaeger, J. C. Friction of rocks and stability of rock slopes. Geotechnique 21, no. 2 (1971): 97-134.

[10] Londe, P., Vigier, G. and Vormeringer, R., Stability of rock slopes-graphical methods. Journal of Soil Mechanics \& Foundations Div, 96 (sm4), (1974): 14111434.

[11] Kulatilake, P. H. S. W., Liangqing Wang, Huiming Tang, and Ye Liang. "Evaluation of rock slope stability for Yujian River dam site by kinematic and block theory analyses." Computers and Geotechnics 38, no. 6 (2011): 846-860.

[12] Yilmaz, Işık. "Comparison of landslide susceptibility mapping methodologies for Koyulhisar, Turkey: conditional probability, logistic regression, artificial neural networks, and support vector machine." Environmental Earth Sciences 61, no. 4 (2010): 821-836.

[13] Chauhan, Shivani, Mukta Sharma, M. K. Arora, and N. K. Gupta. "Landslide susceptibility zonation through ratings derived from artificial neural network." International Journal of Applied Earth Observation and Geoinformation 12, no. 5 (2010): 340350 .
[14] Das, Sarat Kumar, Rajani Kanta Biswal, N. Sivakugan, and Bitanjaya Das. "Classification of slopes and prediction of factor of safety using differential evolution neural networks." Environmental Earth Sciences 64, no. 1 (2011): 201-210.

[15] Lü, Qing, Chin Loong Chan, and Bak Kong Low. "Probabilistic evaluation of ground-support interaction for deep rock excavation using artificial neural network and uniform design." Tunnelling and Underground Space Technology 32 (2012): 1-18.

[16] Yuanyou, Xia, Xie Yanming, and Zhu Ruigeng. "An engineering geology evaluation method based on an artificial neural network and its application." Engineering Geology 47, no. 1-2 (1997): 149-156.

[17] Wang, H. B., W. Y. Xu, and R. C. Xu. "Slope stability evaluation using back propagation neural networks." Engineering Geology 80, no. 3 (2005): 302315.

[18] Gurocak, Zulfu, Selcuk Alemdag, and Musharraf M. Zaman. "Rock slope stability and excavatability assessment of rocks at the Kapikaya dam site, Turkey." Engineering Geology 96, no. 1 (2008): 17-27.

[19] Micheva, Kristina D., Brad Busse, Nicholas C. Weiler, Nancy O'Rourke, and Stephen J. Smith. "Single-synapse analysis of a diverse synapse population: proteomic imaging methods and markers." Neuron 68, no. 4 (2010): 639-653. 